Article

\title{
Estimation of Maize Residue Cover Using Landsat-8 OLI Image Spectral Information and Textural Features
}

\section{Xiuliang Jin ${ }^{1}$, Jianhang Ma ${ }^{1,2}$, Zhidan Wen ${ }^{1}$ and Kaishan Song ${ }^{1, *}$}

1 Key Laboratory of Wetland Ecology and Environment, Northeast Institute of Geography and Agroecology, Chinese Academy of Sciences, Changchun 130102, China;

E-Mails: jinxiuxiuliang@163.com (X.J.); mmjjhh105@sina.com (J.M.); wenzhidan@iga.ac.cn (Z.W.)

2 Department of Cartography and Geographical Information System, University of Chinese Academy of Sciences, Beijing 100049, China

* Author to whom correspondence should be addressed; E-Mail: songks@iga.ac.cn; Tel.: +86-431-8554-2364.

Academic Editors: Mutlu Ozdogan, Sreekala Bajwa and Prasad S. Thenkabail

Received: 25 August 2015 / Accepted: 29 October 2015 / Published: 4 November 2015

\begin{abstract}
The application of crop residue has become increasingly important for providing a barrier against water and wind erosion and improving soil organic matter content, infiltration, evaporation, temperature, and soil structure. The objectives of this work were to: (i) estimate maize residue cover (MRC) from Landsat-8 OLI images using seven vegetation indices (VIs) and eight textural features; and (ii) compare the VI method, textural feature method, and combination method (integration of textural features and spectral information) for estimating MRC with partial least squares regression (PLSR). The results showed that the normalized difference tillage index (NDTI), simple tillage index (STI), normalized difference index 7 (NDI7), and shortwave red normalized difference index (SRNDI) were significantly correlated with MRC. The MRC model based on NDTI outperformed $\left(\mathrm{R}^{2}=0.84\right.$ and $\operatorname{RMSE}=12.33 \%$ ) the models based on the other VIs. Band 3 mean, Band $4_{\text {mean }}$, and Band5mean were highly correlated with MRC. The regression between Band3mean and MRC was stronger $\left(\mathrm{R}^{2}=0.71\right.$ and $\left.\mathrm{RMSE}=15.21 \%\right)$ than those between MRC and the other textural features. The MRC estimation accuracy using the combination method $\left(\mathrm{R}^{2}=0.96\right.$ and $\mathrm{RMSE}=8.11 \%)$ was better than that based on only the VI $\left(\mathrm{R}^{2}=0.88\right.$ and $\left.\mathrm{RMSE}=11.34 \%\right)$ or textural feature $\left(\mathrm{R}^{2}=0.90\right.$ and $\left.\mathrm{RMSE}=9.82 \%\right)$ methods. The results suggest that the combination method can be used to estimate $\mathrm{MRC}$ on a regional scale.
\end{abstract}


Keywords: maize residue cover; Landsat-8 OLI image; spectral information; textural features; estimation

\section{Introduction}

The application of crop residue to agricultural fields after harvest is important for protecting the soil surface against water and wind erosion [1-4]. This agricultural practice also helps improve the soil structure and increase the organic matter content in soil [5], thereby facilitating the biodegradation of pollutants [6]. Thus, management of crop residues is an integral part of many conservation tillage systems. The Conservation Technology Information Center (CTIC) has classified different tillage management strategies (intensive tillage, reduced tillage, and conservation tillage) based on the percentage of crop residue cover [2]. Long-term use of conservation tillage practices can lead to increased soil organic carbon, improved soil structure, and increased aggregation compared with intensively tilled soils [5]. Crop residue estimates are also a critical parameter for soil carbon estimations and in modeling and monitoring improvements in carbon sequestration that result from changes in land management approaches. Therefore, it is important to estimate crop residue cover (CRC) on agricultural land at a regional scale. However, the traditional survey-based methods for quantifying CRC over large areas are time consuming, unsuitable, and costly [7].

Remote sensing is a useful tool to efficiently quantify CRC on a regional scale and provides spatial information of CRC within crop fields [7-11]. Early attempts to estimate CRC using remote sensing techniques began in 1975 [12]. Over the past few decades, several methods have been used to estimate CRC in different regions based on multispectral and hyperspectral remote sensing data and spectroradiometric ground measurements of soil type, residue type, and residue percentage [7-11,13,14]. McNairn and Protz [15] analyzed the relationship between CRC and the normalized difference index (NDI) under different soil conditions using Landsat-5 Thematic Mapper (TM) data; the results presented a strong linear relationship between NDI and maize residue cover $\left(\mathrm{R}^{2}=0.65-0.84\right)$. van Deventer et al. [16] studied the relationships between the simple tillage index (STI), normalized difference tillage index (NDTI), and CRC using bands five and seven of Landsat-5 TM data, and good relationships were exhibited between these parameters. Daughtry [8] proposed the cellulose absorption index (CAI) based on cellulose and lignin absorption features near $2100 \mathrm{~nm}$ to discriminate crop residue from soil using in situ spectra acquired with the GER 3700 spectroradiometer. Furthermore, Daughtry et al. [9] showed that CRC was linearly related to CAI $\left(\mathrm{R}^{2}=0.89\right)$. High estimation accuracy $\left(\mathrm{R}^{2}=0.91\right)$ between the normalized difference senescent vegetation index (NDSVI) and fractional senescent vegetation cover was achieved using a two-component linear unmixing analysis [17]. Crop residue cover has been estimated and mapped on agricultural land using hyperspectral and IKONOS data to demonstrate the strong relationship between predicted and measured CRC (index of agreement $(D)=0.92$ ) [10]. The shortwave infrared normalized difference residue index (SINDRI) derived from ASTER bands six and seven is strongly related to CRC $\left(\mathrm{R}^{2}=0.74\right)$ [14]. Pacheco and McNairn [7] estimated CRC based on SPOT and Landsat-5 TM data, and good consistency between the predicted and measured CRC was obtained using the spectral unmixing method. Zheng et al. [18,19] applied the minimum NDTI 
(minNDTI) to estimate CRC based on a time series of Landsat TM and Enhanced TM Plus (ETM+) data $\left(\mathrm{R}^{2}=0.89\right)$. Bocco et al. [20] estimated CRC using neural network $(\mathrm{NN})$ and crop residue index multiband (CRIM) models from Landsat TM and ETM+ image data, and the results showed that both methodologies were appropriate for estimating CRC from Landsat data $\left(R^{2}=0.95\right.$ for the $\mathrm{NN}$ model and $\mathrm{R}^{2}=0.87$ for the CRIM model).

The textural feature method can be used to extract textural features through image processing techniques and to analyze texture either quantitatively or qualitatively [21]. Image texture analysis involves measuring heterogeneity in the tonal values of pixels within a defined area of an image [22], and this method has been used to estimate parameters of vegetative structure [23,24]. Empirical models have been developed to study the relationships between vegetation indices (VIs) and CRC on regional scales. However, the use of textural features for estimating CRC has not been thoroughly investigated. Darvishzadeh et al. [25] reported that using full spectral subsets or the maximum amount of spectral information available will require more computation time but is not likely to increase estimation accuracy. Moreover, several features are sufficient for obtaining the essential information to estimate LAI, nitrogen concentration, and vegetation classification [26-29].

Maize is the main crop in the Songnen Plain, which is an important food production base in China. The estimation of maize residue cover (MRC) for this crop is important for agricultural production and management in this region. The distribution of MRC throughout an agricultural field can be highly heterogeneous, so it is difficult to effectively obtain MRC at a regional scale. Moreover, previous studies have failed to clearly describe the CRC estimation accuracy using Landsat-8 OLI imagery data. Therefore, the main purpose of this study was to accurately estimate MRC using Landsat-8 OLI imagery data in the Songnen Plain. The specific objectives of this study were to: (1) investigate the potential of Landsat- 8 OLI images for MRC estimation using seven VIs and eight textural features; and (2) compare the VI, textural feature, and combination (combination of VIs and textural features) methods for estimating CRC with partial least squares regression (PLSR). The results provide a guideline for estimating MRC based on spectral information and textural features on a regional scale. This method to measure percent $\mathrm{MRC}$ is, thus, adequate for policy and program development, land management decision-makers, and carbon modelers.

\section{Material and Methods}

\subsection{Study Area}

The study area was located between Changchun $\left(43^{\circ} 5^{\prime} \mathrm{N}-45^{\circ} 15^{\prime} \mathrm{N}, 124^{\circ} 18^{\prime} \mathrm{E}-127^{\circ} 2^{\prime} \mathrm{E}\right)$, Jilin Province, and Suihua $\left(45^{\circ} 3^{\prime} \mathrm{N}-48^{\circ} 2^{\prime} \mathrm{N}, 124^{\circ} 13^{\prime} \mathrm{E}-128^{\circ} 30^{\prime} \mathrm{E}\right)$ in Heilongjiang Province, Northeast China (Figure 1). This area is part of the Songnen Plain, which is the main distribution area of spring maize. Maize cultivation covers about 80\% [30] of the arable land in the Songnen Plain. This area is under a typical semi-humid northern temperate monsoon continental climate. The average maximum temperature is $23.5{ }^{\circ} \mathrm{C}$ in the summer, and the average minimum temperature is $-13.3{ }^{\circ} \mathrm{C}$ in the winter. The average annual precipitation ranges from 522 to $615 \mathrm{~mm}$, and the average frost-free period lasts for 120 to $150 \mathrm{~d}$. Local maize cultivars are planted and harvested in May and October, respectively. 


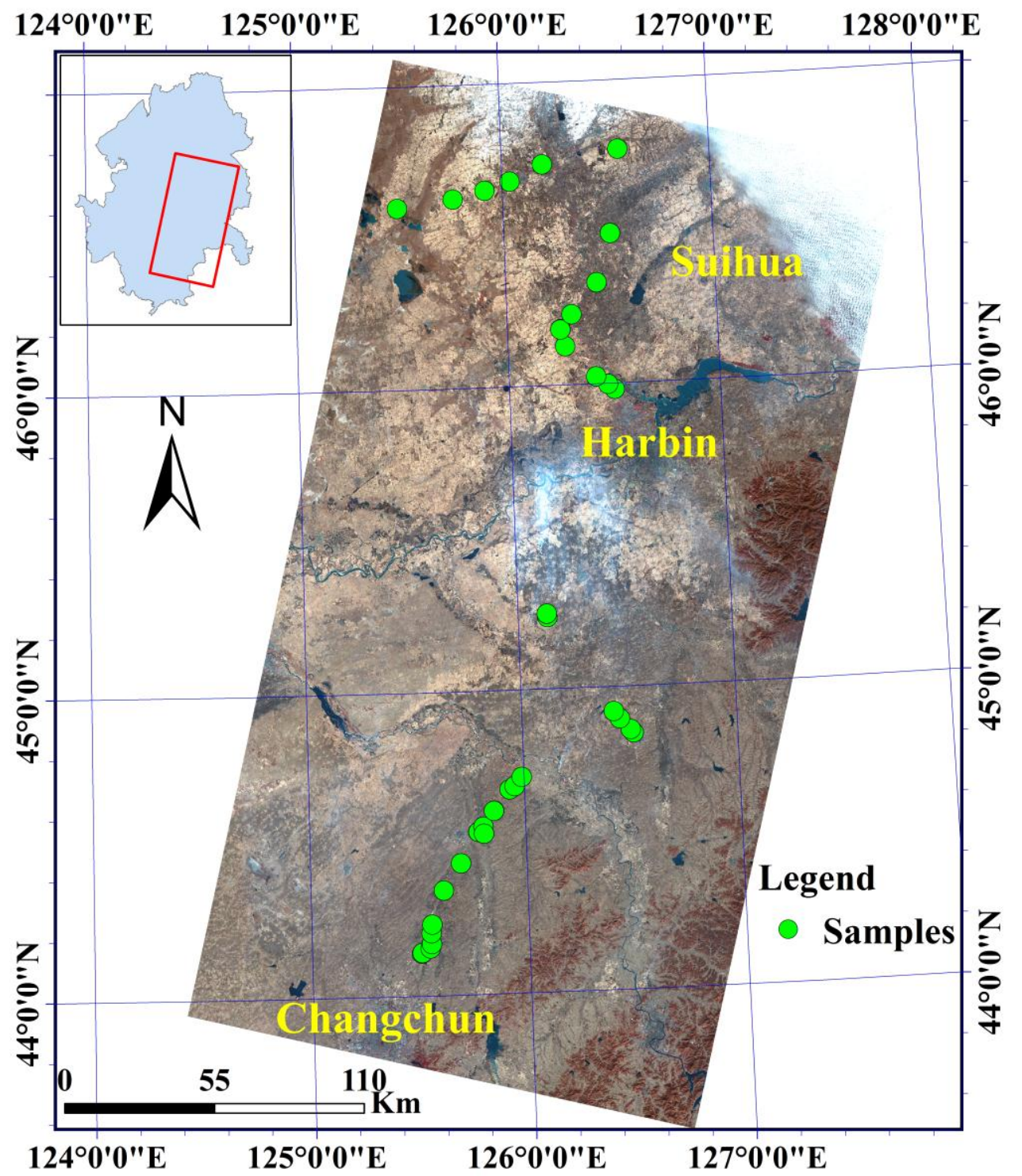

Figure 1. Sample locations (false color composite Landsat- 8 image, acquired on 4 November 2014; R/G/B vs. band5/band4/band3).

\subsection{Field Measurements}

The MRC at field sites was measured using the line transect method [31] from 31 October to 6 November 2014 (Figure 2). We used a 100-ft (29.85 m) measuring tape, which could be easily divided into 100 parts with $1 \mathrm{ft}$ intervals, shown as red markings, to make the measurements. At each sampling site, the tape was stretched diagonally across rows [32] and the number of markings intersecting crop residue was counted. Percent cover was calculated as the average of the marking numbers. In addition, we used a UniStrong G3 GPS unit (positional accuracy $<5 \mathrm{~m}$ ) to record the location of each measurement site, acquire photographs, and record information for each site. We measured a total of 36 fields. In this study, each sample plot is an adequate representation of a much greater area $\left(>50,000 \mathrm{~m}^{2}\right)$. The area of each sample plot was $\sim 1781.68 \mathrm{~m}^{2}$. The MRC data were randomly divided into two parts using SPSS software (16.0, SPSS, Chicago, IBM, Armonk, NY, USA): a calibration dataset with 24 samples and a validation dataset with 12 samples. The calibration dataset was used to establish the regression equations 
between MRC and vegetation indices. The validation dataset was used to evaluate the consistency between the predicted and measured MRC. The statistics of each subset for MRC are summarized in Table 1. As shown in Table 1, the MRC for the calibration dataset ranged from $10.00 \%$ to $95.00 \%$, with an average of $60.04 \%$ and a standard deviation of $27.19 \%$. Similarly, the corresponding values for the validation dataset were $10.90 \%, 89.00 \%, 59.60 \%$, and $27.69 \%$, respectively. Table 1 showed that the calibration dataset and the validation dataset differed. The range of the calibration dataset was larger than the range of the validation dataset. The mean of the calibration dataset was higher than the mean of the validation dataset. However, the standard deviation of the calibration dataset was higher than the standard deviation of the validation dataset.

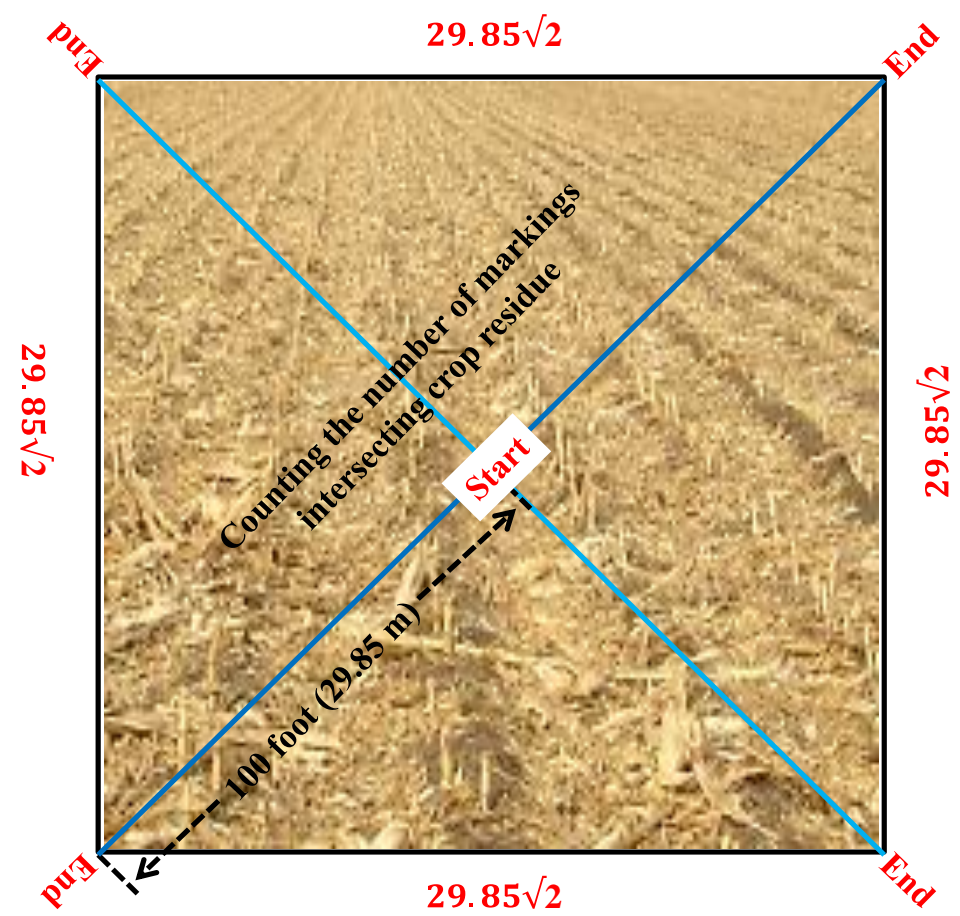

Figure 2. Maize residue cover sampling design in this study.

Table 1. Descriptive statistics of maize residue cover (\%) in the study area.

\begin{tabular}{cccccc}
\hline Dataset & Samples & Max & Min & Mean & Standard Deviation \\
\hline Calibration dataset & 24 & 95.00 & 10.00 & 60.04 & 27.19 \\
Validation dataset & 12 & 89.00 & 10.90 & 59.60 & 27.67 \\
\hline
\end{tabular}

\subsection{Remote Sensing Data and Pre-Processing}

Two Landsat-8 OLI satellite images were obtained from the United States Geological Survey (USGS) website (http://glovis.usgs.gov/). The corresponding lines and rows were 118 and 028, and 118 and 029 on 4 November 2014. The Landsat-8 OLI satellite images were processed (including radiometric calibration, atmospheric correction, and geometric correction) using ENVI 4.7 software. Land surface reflectance was then retrieved using the Fast Line-of-Sight Atmospheric Analysis of Spectral Hypercubes (FLAASH) module. Each Landsat-8 OLI image was co-registered with a geo-referenced Landsat TM image at a geometric accuracy of $<0.5$ pixels. Since the area of each sample plot was $\sim 1781.68 \mathrm{~m}^{2}$, nine pixels of Landsat-8 OLI satellite image data were corrected to match the ground sample plot. 


\subsection{Methods}

\subsubsection{Vegetation Indices}

Our study included seven vegetation indices (VIs). Six were derived from previous studies, and the remaining one was developed in this study (Table 2, [15-17,33]). The previous studies indicated that the six VIs were correlated with CRC.

Table 2. Summary of selected satellite optical vegetation indices, wavebands, and references for crop residue cover estimation.

\begin{tabular}{cccc}
\hline Vegetation Index & Abbreviation & Formula & References \\
\hline Simple tillage index & STI & B6/B7 & {$[16]$} \\
Normalized difference tillage index & NDTI & $(\mathrm{B} 6-\mathrm{B} 7) /(\mathrm{B} 6+\mathrm{B} 7)$ & {$[16]$} \\
Modified crop residue cover & MCRC & $(\mathrm{B} 6-\mathrm{B} 3) /(\mathrm{B} 6+\mathrm{B} 3)$ & {$[33]$} \\
Normalized difference index 5 & NDI5 & $(\mathrm{B} 5-\mathrm{B} 6) /(\mathrm{B} 5+\mathrm{B} 6)$ & {$[15]$} \\
Normalized difference index 7 & NDI7 & $(\mathrm{B} 5-\mathrm{B} 7) /(\mathrm{B} 5+\mathrm{B} 7)$ & {$[15]$} \\
Shortwave red normalized difference index & SRNDI & $(\mathrm{B} 7-\mathrm{B} 4) /(\mathrm{B} 7+\mathrm{B} 4)$ & In this paper \\
Normalized difference senescent vegetation index & NDSVI & $(\mathrm{B} 6-\mathrm{B} 4) /(\mathrm{B} 6+\mathrm{B} 4)$ & {$[17]$} \\
\hline
\end{tabular}

Note: B2 $(0.450-0.515 \mu \mathrm{m}) ; \mathrm{B} 3 \quad(0.525-0.600 \mu \mathrm{m}) ; \mathrm{B} 4 \quad(0.630-0.680 \mu \mathrm{m})$; B5 $(0.845-0.885 \mu \mathrm{m})$; B6 $(1.560-1.660 \mu \mathrm{m})$; B7 $(2.100-2.300 \mu \mathrm{m})$ : Landsat-8 OLI bands $2-7$, and corresponding Landsat TM and ETM+ bands $1-5$ and 7.

\subsubsection{Textural Features}

Textural features were statistically obtained with a gray level co-occurrence matrix (GLCM). Many such metrics can be derived from this matrix. In this study, we selected eight textural feature metrics, including the mean, variance, homogeneity, contrast, dissimilarity, entropy, second moment, and correlation [22]. We calculated the textural features of each Landsat-8 OLI image by analyzing the eight metrics with a window size of $3 \times 3$ pixels, which matched the scale at which our MRC data were collected from the ground.

\subsubsection{Extraction of Maize Cultivation Area}

The maximum likelihood method was used to extract the maize cultivation area from the Landsat- 8 OLI satellite image data and remove the effect of built-up areas, water, forests, and roads. This technique assumes that the statistics for each class of each band are normally distributed and calculates the probability that a given pixel belongs to a specific class [34]. Unless a probability threshold is selected, all pixels are classified. Each pixel is assigned to the class with the highest probability. If the highest probability is smaller than the threshold specified, the pixel will remain unclassified. The ENVI 4.7 software completed the classification according to 280 field survey points with known land cover types. The overall accuracy of the extracted maize cultivation area was $94 \%$, which satisfied the requirements of this study.

\subsubsection{Partial Least Squares Regression}

The PLSR technique generalizes and combines regression modeling (multiple linear regressions), data structure analysis (principal component analysis, PCA), and correlation analysis between two sets 
of variables (canonical correlation analysis). The method is a powerful modeling tool that reduces large numbers of measured collinear VIs to a few non-correlated latent variables or factors [35,36]. The noise and collinearity in the original spectra are thus significantly eliminated from the condensed components. The optimal number of factors in PLSR analysis is determined by minimizing the prediction residual error sum of the squares statistic. Compared with PLSR, PCA only summarizes the information of independent variable, and does not consider the relationships between the independent variables and dependent variables; therefore, it loses useful information when extracting the principal component. The PLSR technique not only considers the information of the independent variable, but it also considers the relationships between the independent and dependent variables. Therefore, the stability of PLSR is better than that of PCA.

PLSR models are an extension of multiple linear regression models (e.g., multiple or general stepwise regressions). This method is particularly useful when one needs to predict a set of dependent variables from a large set of independent variables. In its simplest form, a linear model specifies the (linear) relationship between a dependent (response) variable y and a set of predictor (x) variables [37]:

$$
\mathrm{y}=\mathrm{b}_{0}+\mathrm{b}_{1} \mathrm{x}_{1}+\mathrm{b}_{2} \mathrm{x}_{2}+\mathrm{b}_{3} \mathrm{x}_{3}+\ldots+\mathrm{b}_{\mathrm{p}} \mathrm{x}_{\mathrm{p}}
$$

where $b_{0}$ is the regression coefficient for the intercept and the $b_{i}$ values are regression coefficients (for variables 1 to $\mathrm{p}$ ) computed from the data.

\subsection{Statistical Analysis}

The relationships between MRC and VIs/textural features were analyzed. The coefficient of determination $\left(\mathrm{R}^{2}\right)$ and root mean square error (RMSE) were used to quantify the amount of variation explained by the developed relationships and the accuracy of the relationships. Generally, the performance of a model is determined by comparing the differences in the $\mathrm{R}^{2}$ and RMSE values. Higher $\mathrm{R}^{2}$ values correspond to lower RMSE values and a higher precision and accuracy of a model for predicting MRC [38].

\section{Results}

\subsection{Relationship between Maize Residue Cover and Vegetation Indices}

We found significant relationships between the VIs and MRC based on linear and nonlinear regressions (Table 3). The NDTI-MRC and MCRC-MRC regressions had the highest and lowest $\mathrm{R}^{2}$ values ( 0.84 and 0.50 , respectively). The order of the VIs from highest to lowest with respect to the $\mathrm{R}^{2}$ values of the MRC regression relationships was NDTI, STI, NDI7, SRNDI, NDI5, NDSVI, and MCRC. Of the $\mathrm{R}^{2}$ values, one was above 0.80 , four were above 0.70 , and two were below 0.6. The MCRC was fit to a linear equation; NDI5, NDI7, SRNDI, and NDSVI were fit to exponential equations; and STI and NDTI were fit to power equations. These $\mathrm{R}^{2}$ values were adjusted, as the adjusted $\mathrm{R}^{2}$ values better demonstrate the relationships between MCR and VIs. To validate the estimation accuracy of the MRC regression equations, we compared the predicted and measured MRC values. The RMSE values ranged from $12.33 \%$ to $21.16 \%$ (Table 3). These results suggested that NDTI, STI, NDI7, and SRNDI can be used to estimate MRC (Table 3 and Figure 3). 
Table 3. Relationships between maize residue cover and vegetation indices.

\begin{tabular}{cccc}
\hline Vegetation Index & Regression Equation & $\mathbf{R}^{2}$ & RMSE (\%) \\
\hline NDTI & $\mathrm{y}=577.2 \mathrm{x}^{1.379}$ & $0.84^{* *}$ & 12.33 \\
STI & $\mathrm{y}=9.579 \mathrm{x}^{4.428}$ & $0.78^{* *}$ & 13.71 \\
NDI7 & $\mathrm{y}=40.15 \mathrm{e}^{3.538 \mathrm{x}}$ & $0.72^{* *}$ & 14.63 \\
SRNDI & $\mathrm{y}=101.7 \mathrm{e}^{-3.89 \mathrm{x}}$ & $0.71^{* *}$ & 14.71 \\
NDI5 & $\mathrm{y}=96.90 \mathrm{e}^{5.429 \mathrm{x}}$ & $0.63^{* *}$ & 17.65 \\
NDSVI & $\mathrm{y}=463.9 \mathrm{e}^{-6.24 \mathrm{x}}$ & $0.57^{* *}$ & 18.56 \\
MCRC & $\mathrm{y}=243.4 \mathrm{x}-43.49$ & $0.50^{* *}$ & 21.16 \\
\hline
\end{tabular}

Note: ** indicates a significant relationship at the 0.01 probability level.
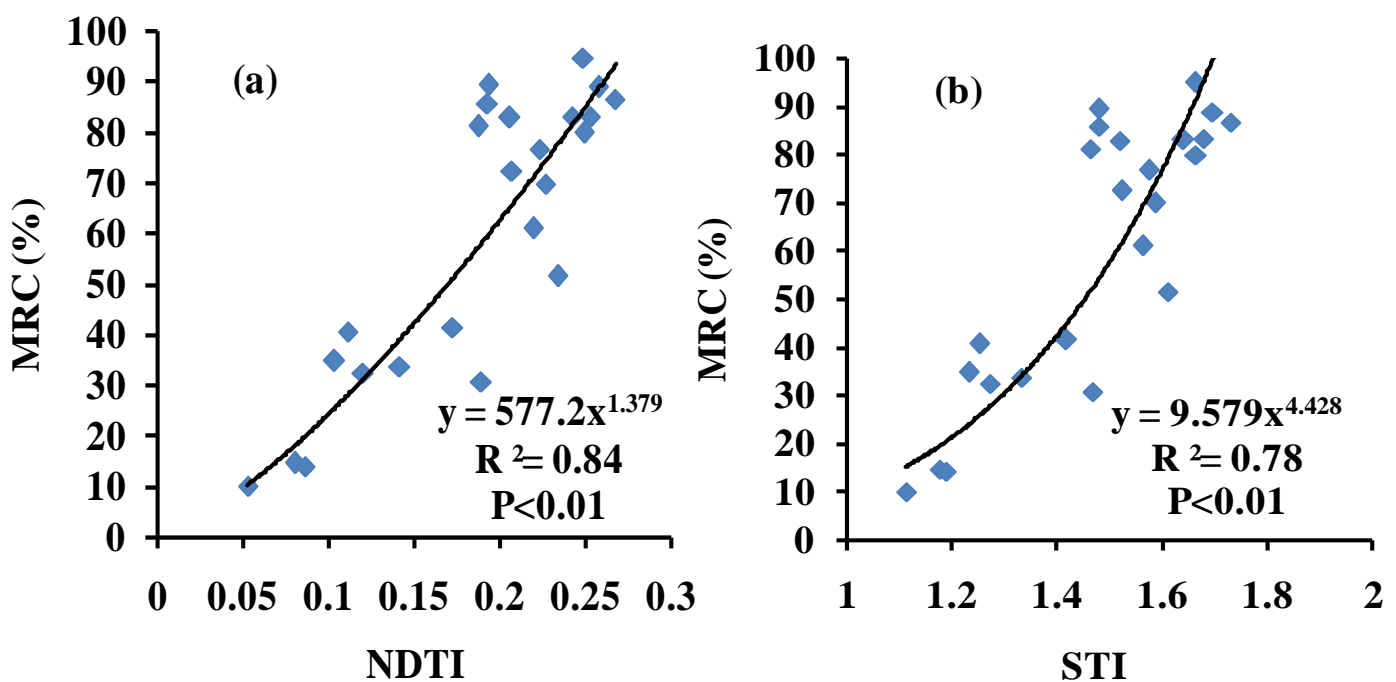

Figure 3. Regression between MRC and (a) NDTI; (b) STI.

\subsection{Relationship between Maize Residue Cover and Textural Features}

Eight textural feature indicators (i.e., mean, variance, homogeneity, contrast, dissimilarity, entropy, second moment, and correlation) were calculated to examine the regression relationships between each textural feature indicator and MRC. The results showed that 10 textural feature indicators were significantly correlated with MRC (Table 4). All of the textural feature indicators were highly correlated

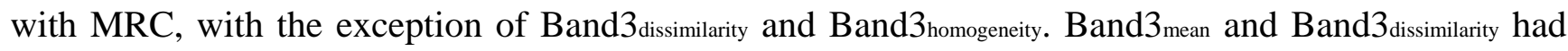
the strongest $\left(R^{2}=0.71\right)$ and weakest $\left(R^{2}=0.21\right)$ relationships with $M R C$, respectively. The $R^{2}$ values of the 10 textural feature metrics ranged from 0.21 to 0.67 , and the corresponding order of the textural

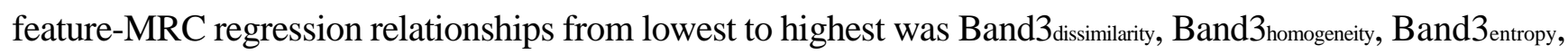

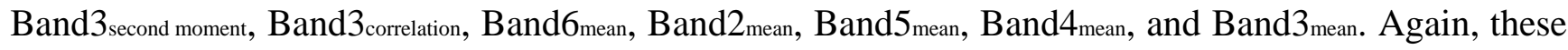
$\mathrm{R}^{2}$ values were adjusted, as the adjusted $\mathrm{R}^{2}$ values better demonstrate the relationship between MCR and textural features. To validate the estimation accuracy of the MRC models, the predicted and measured values were compared. The RMSE values ranged from $15.21 \%$ to $26.35 \%$ (Table 4). The RMSE values indicate the prediction power of the estimation equation for MRC. The lower RMSE values show that the estimation equation for MRC had better prediction accuracy. These statistical criteria ( $\mathrm{R}^{2}$ and RMSE) were comprehensively considered to select the best fitting regression equation for estimating MRC. Therefore, Band 3 mean-Band5 mean were used to estimate MRC (Table 4 and Figure 4). 


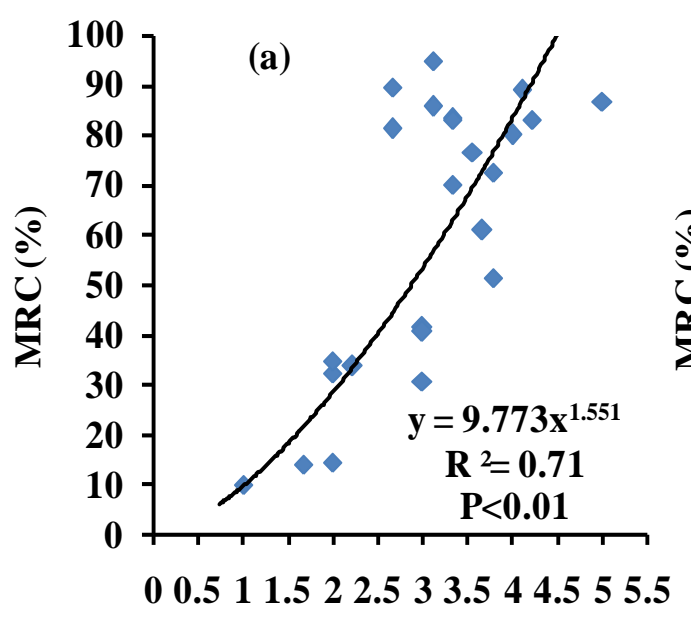

Band $3_{\text {mean }}$

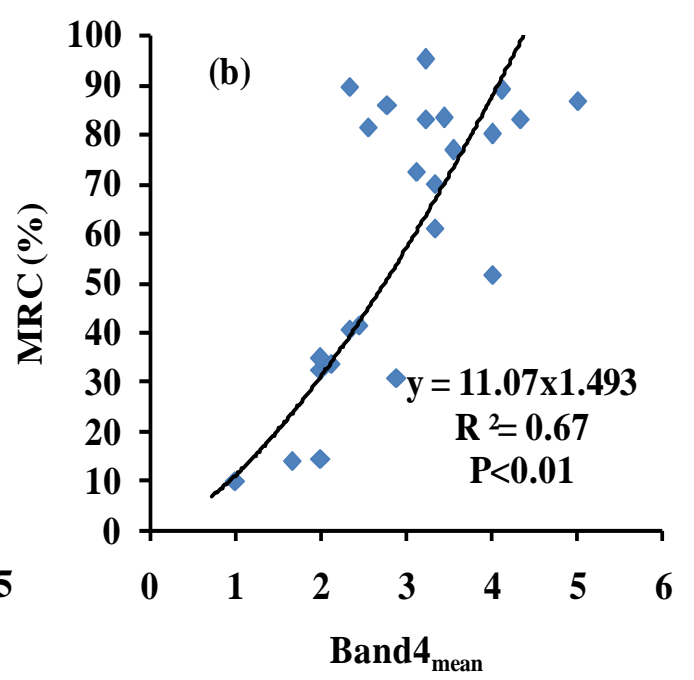

Figure 4. Regression between MRC and (a) Band $3_{\text {mean, }}$ and (b) Band 4 mean.

Table 4. Relationships between maize residue cover and textural feature indicators.

\begin{tabular}{cccc}
\hline Texture Feature Indicators & Regression Equation & $\mathbf{R}^{\mathbf{2}}$ & RMSE (\%) \\
\hline Band $3_{\text {mean }}$ & $\mathrm{y}=9.773 \mathrm{x}^{1.551}$ & $0.71^{* *}$ & 15.21 \\
Band $4_{\text {mean }}$ & $\mathrm{y}=11.07 \mathrm{x}^{1.493}$ & $0.67^{* *}$ & 19.45 \\
Band $5_{\text {mean }}$ & $\mathrm{y}=5.116 \mathrm{x}^{1.485}$ & $0.65^{* *}$ & 20.02 \\
Band $2_{\text {mean }}$ & $\mathrm{y}=0.463 \mathrm{x}^{3.260}$ & $0.52^{* *}$ & 16.92 \\
Band6 & $\mathrm{y}=30.42 \mathrm{x}-1004$ & $0.43^{* *}$ & 21.72 \\
Band $3_{\text {correlation }}$ & $\mathrm{y}=-31.77 \mathrm{x}+75.72$ & $0.42^{* *}$ & 21.81 \\
Band3 $3_{\text {second moment }}$ & $\mathrm{y}=-27.9 \ln (\mathrm{x})+39.94$ & $0.37^{* *}$ & 23.31 \\
Band3 $3_{\text {entropy }}$ & $\mathrm{y}=26.05 \mathrm{x}+39.2$ & $0.36^{* *}$ & 22.43 \\
Band3 $3_{\text {homogeneity }}$ & $\mathrm{y}=-101.8 \mathrm{x}+146.4$ & $0.26^{*}$ & 24.43 \\
Band3 $3_{\text {dissimilarity }}$ & $\mathrm{y}=40.99 \mathrm{x}+46.75$ & $0.21^{*}$ & 26.35 \\
\hline
\end{tabular}

Note: Band $2_{\text {mean }}$ represents the mean texture of Band2; Band $3_{\text {mean }}$, Band $3_{\text {homogeneity }}$, Band $3_{\text {dissimilarity }}$, Band $3_{\text {entropy, }}$

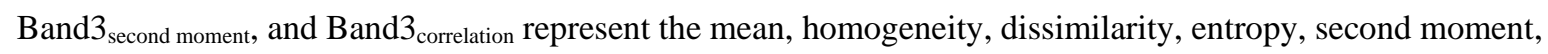
and correlation texture of Band 3 , respectively; Band 4 mean represents the mean texture of Band4; Band 5 mean represents the mean texture of Band5; Band6 mean represents the mean texture of Band6; ${ }^{* *}$ and ${ }^{*}$ indicate a significant relationship at the 0.05 and 0.01 probability levels, respectively.

\subsection{Estimating MRC via Partial Least Squares Regression (PLSR)}

Three methods (VI, textural feature, and combination method) for estimating MRC via PLSR were compared (Table 5). For the VI methods, NDTI, STI, NDI7, and SRNDI were selected to estimate MRC using PLSR because they had high $\mathrm{R}^{2}$ and low RMSE values, and the $\mathrm{R}^{2}$ and RMSE values of the regression equation were 0.87 and $11.36 \%$, respectively. The $\mathrm{R}^{2}$ and RMSE values of the MRC model based on all the VIs were 0.88 and $11.34 \%$, respectively. Thus, the addition of MCRC, NDI5, and NDSVI to the model did not significantly improve the MRC estimation accuracy. For the textural feature method, Band 3 mean, Band4 $4_{\text {mean }}$ and Band5 mean were used to estimate MRC by PLSR because they had high $\mathrm{R}^{2}$ and low RMSE values, and the $\mathrm{R}^{2}$ and RMSE values were 0.83 and $12.32 \%$, respectively. The $\mathrm{R}^{2}$ and RMSE values of the MRC regression equation based on all the textural features were 0.90 and $9.82 \%$, respectively. The MRC estimation accuracy was further improved using PLSR based on all the textural 
features. For the combination method (the integration of textural features and spectral information), four VIs (NDTI, STI, NDI7, and SRNDI) and three textural feature indicators (Band3mean-Band5mean) were selected to estimate MRC via PLSR, and the $\mathrm{R}^{2}$ and RMSE values for the model were 0.95 and $8.43 \%$, respectively. The combination method based on all the VIs and textural feature indicators were selected to estimate MRC via PLSR, and the $\mathrm{R}^{2}$ and RMSE values for the model were 0.96 and $8.11 \%$, respectively. The MRC estimation accuracy was higher using the combination method than the VI and textural feature methods alone (Table 5 and Figure 5). Thus, the combination method can be used to estimate MRC.
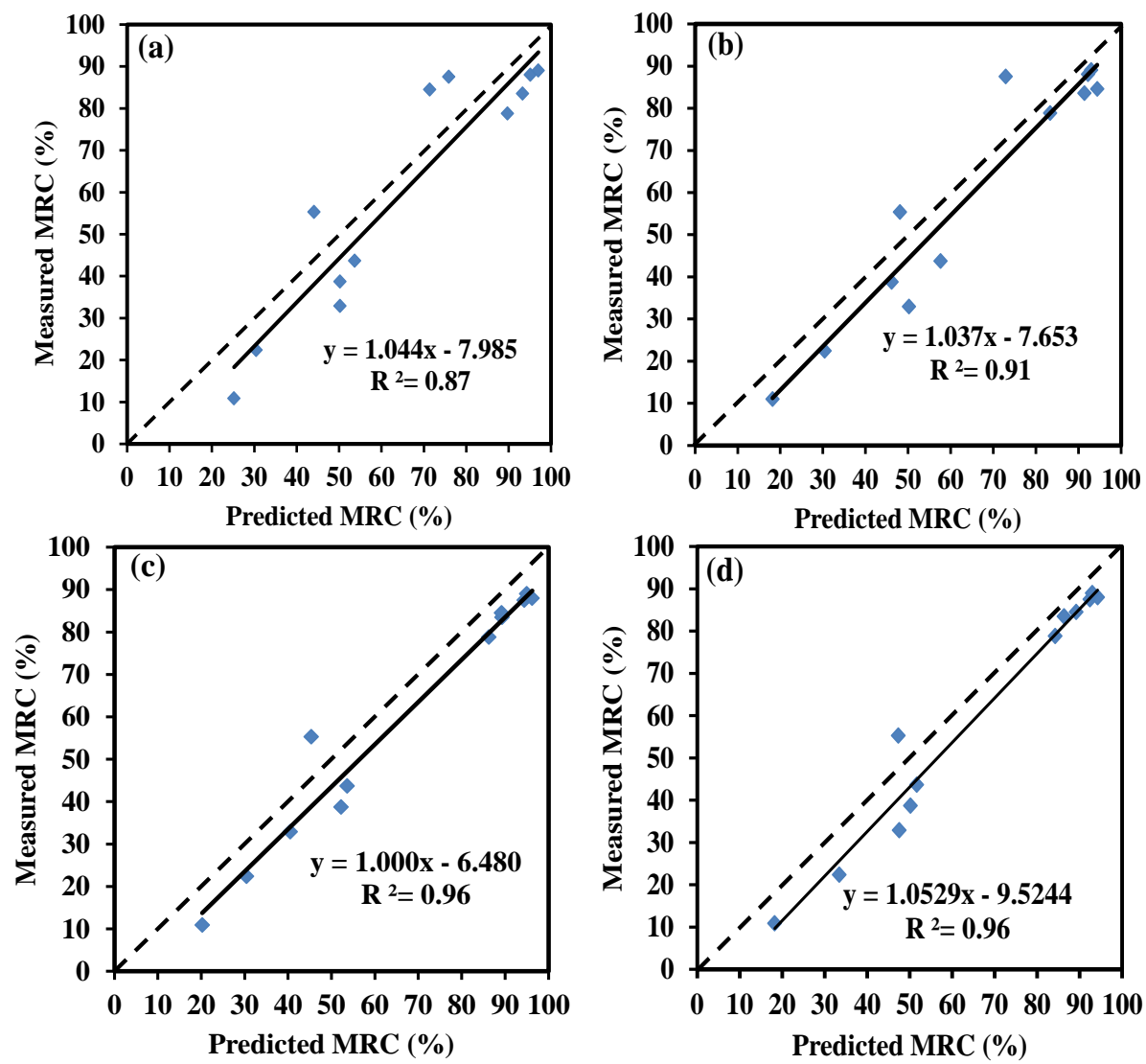

Figure 5. Relationships between predicted and measured MRC: (a) VI method; (b) textural feature method; (c) combination method; and (d) combination method based on all VIs and textural feature indicators.

Table 5. Comparison of three methods for estimating of maize residue cover using partial least squares regression.

\begin{tabular}{|c|c|c|c|}
\hline Methods & Factor & $\mathbf{R}^{2}$ & RMSE (\%) \\
\hline \multirow{2}{*}{ Vegetation indices } & NDTI, STI, NDI7, and SRNDI & 0.87 & 11.36 \\
\hline & STI, NDTI, MCRC, NDI5, NDI7, SRNDI, NDSVI & 0.88 & 11.34 \\
\hline \multirow[b]{2}{*}{ Texture features } & Band $3_{\text {mean }}$, Band $4_{\text {mean }}$, Band $5_{\text {mean }}$ & 0.83 & 12.32 \\
\hline & $\begin{array}{c}\text { Band } 2_{\text {mean }}, \text { Band } 3_{\text {mean }}, \text { Band } 3_{\text {homogeneity }}, \text { Band } 3_{\text {dissimilarity }}, \text { Band } 3_{\text {entropy }}, \\
\text { Band } 3_{\text {second moment }} \text {, Band } 3_{\text {correlation }}, \text { Band } 6_{\text {mean }}\end{array}$ & 0.90 & 9.82 \\
\hline \multirow[b]{2}{*}{ Combination } & NDI7, SINDI, STI, NDTI, Band $3_{\text {mean }}$, Band $4_{\text {mean }}$, Band $5_{\text {mean }}$ & 0.95 & 8.43 \\
\hline & $\begin{array}{l}\text { STI, NDTI, MCRC, NDI5, NDI7, SRNDI, NDSVI, Band } 2_{\text {mean }} \text {, } \\
\text { Band } 3_{\text {mean }}, \text { Band } 3_{\text {homogeneity }}, \text { Band } 3_{\text {dissimilarity }}, \text { Band } 3_{\text {entropy }}, \\
\text { Band } 3_{\text {second moment }} \text { Band } 3_{\text {correlation }}, \text { Band } 6_{\text {mean }}\end{array}$ & 0.96 & 8.11 \\
\hline
\end{tabular}




\subsection{MRC Mapping}

The spatial distribution of MRC was estimated based on all VIs and texture feature indicators via the combination method (Figure 6). The MRC ranged from 7\% to $98 \%$ over the entire Songnen Plain. The MRC occupying $14.92 \%, 19.15 \%$, and $20.47 \%$ of the maize cultivation area ranged from $7 \%$ to $25 \%$, from $25 \%$ to $50 \%$, and from $50 \%$ to $75 \%$, respectively. Of the cultivated area, $22.89 \%$ had MRC ranging from $75 \%$ to $85 \%$ and $22.57 \%$ had MRC ranging from $85 \%$ to $98 \%$. These results were consistent with our field observations. The highest and lowest overall MRC was measured in Suihua and Changchun, respectively, and the measured MRC in Harbin was between these two values.

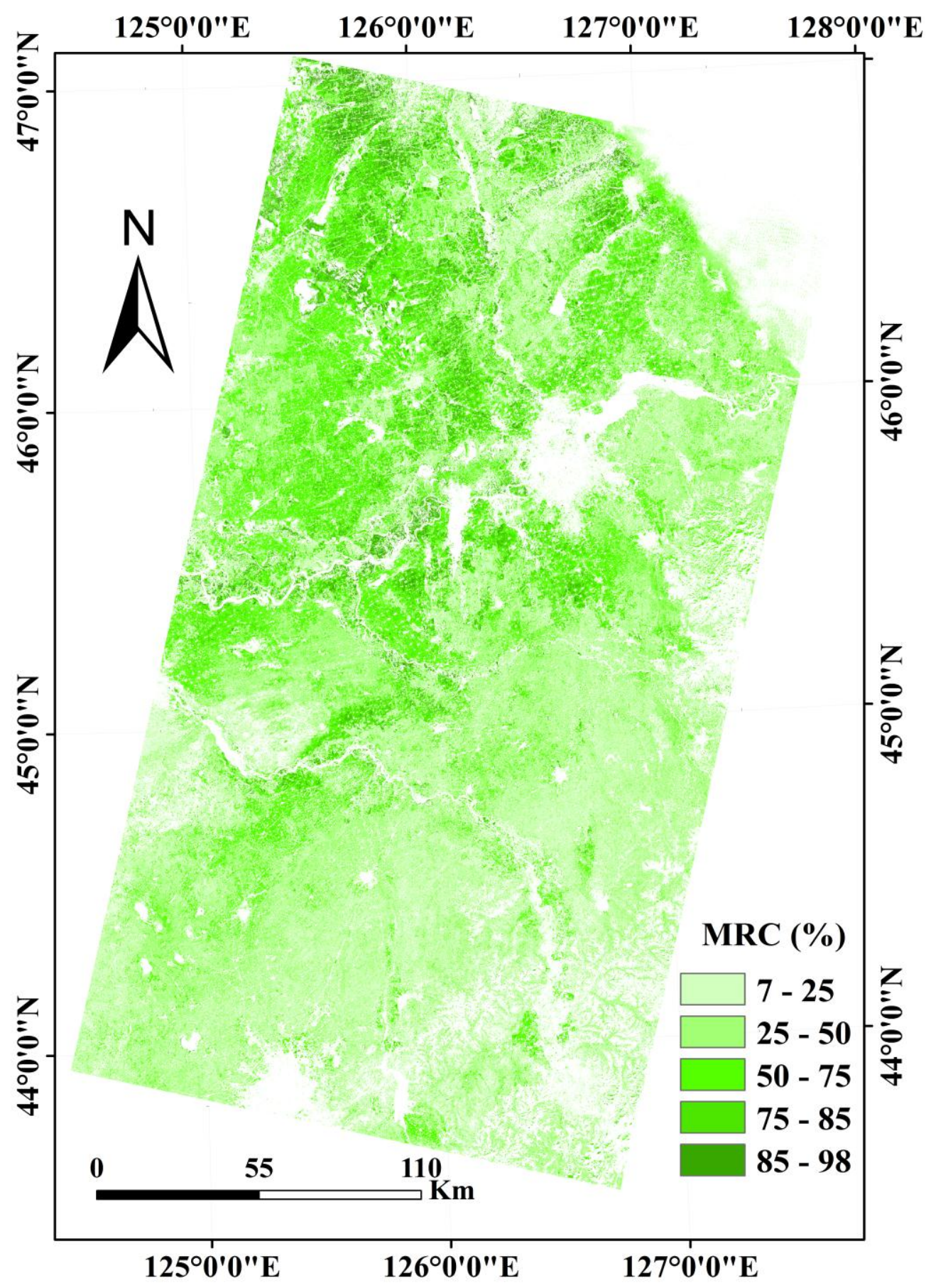

Figure 6. Spatial distribution of MRC in the Songnen Plain. 


\section{Discussion}

In this study, the sample data was divided into a calibration set and validation set, which is a method that has commonly been used in previous studies. Many scientists have used this method to carry out related studies [39-45]. These studies have indicated that this method can be used to obtain good estimation results. In this paper, the amount of sample data was suitable for the statistical requirements. There were some differences between the two groups, which reflect the stability of the estimation model. Finally, the results of the estimation model show that the results of this study are representative.

All of the investigated VIs were significantly correlated with MRC, particularly NDTI, STI, NDI7, and SRNDI (Table 3). Daughtry et al. [9] indicated that two major water absorption bands exist near 1450 and $1960 \mathrm{~nm}$, and oven-dried and water-saturated residues have the highest and lowest spectrum, respectively. Murray and Williams [39] suggested that a broad absorption feature near $2100 \mathrm{~nm}$ is also evident in the reflectance spectra of all dry crop residues, which is probably associated with lignin and cellulose in crop residue. Thus, spectral information at 1450-1960 nm and near $2100 \mathrm{~nm}$ is highly correlated with CRC and can be used to estimate CRC [4,10,14,16,18,19]. NDTI and STI were calculated from bands six (1560-1660 nm) and seven (2100-2300 nm) of the Landsat-8 OLI image data, and the NDTI-MRC and STI-MRC regressions yielded $\mathrm{R}^{2}$ values of 0.84 and 0.78 , respectively (Table 3). Our results were consistent with those of Zheng et al. [18,19] and Galloza et al. [11], indicating that it is feasible to estimate MRC using NDTI or STI from Landsat-8 OLI images. The NDI7 values were calculated from bands five $(845-885 \mathrm{~nm}$ ) and seven of the Landsat-8 OLI imagery data. Previous results have indicated that band five is highly correlated with CRC because of the sensitivity of near infrared wavelengths to plant structure [46], meaning that crop residue has a higher reflectance than bare soil in this band [15]. Therefore, NDI7 was significantly related to CRC in this study. Qi et al. [17] proposed SRNDI based on bands four $(630-680 \mathrm{~nm})$ and seven, and our results showed that SRNDI was better correlated with CRC than NDSVI (Table 3). Daughtry et al. [8,47] indicated that the cellulose absorption index (CAI) is a better proxy than the other VIs for estimating crop residues based on cellulose and lignin absorption features near $2100 \mathrm{~nm}$. This may explain why SRNDI performed better than NDSVI in this study. Our results also suggested that NDTI, STI, NDI7, and SRNDI can be used to estimate MRC on a regional scale.

Previous findings have indicated that textural features can be used to estimate LAI and improve the estimation accuracy of aboveground biomass in forests [48-50]. In the current study, 10 textural feature metrics presented a good relationship with CRC. Band 3 mean, Band 4 mean, and Band5 mean were significantly correlated with CRC (Table 4), which is consistent with the results of previous studies [22,51].Thus, the 10 textural feature indicators investigated in the current study can be used to estimate MRC, which further confirms the results of previous studies $[48,50]$.

The results showed that NDTI, STI, NDI7 and SRNDI were highly correlated with MRC using PLSR (Table 5). This may be because the PLSR method fully considers the relationships between the covariance of VIs and MRC variables by applying data compression into regression factors. Previous studies have shown that PLSR can be used to improve the estimation accuracy of biophysical and biochemical parameters [11,52]. However, our results showed that the addition of MCRC, NDI5, and NDSVI to the PLSR did not significantly improve the CRC estimation accuracy. Li et al. [26] and Mutanga et al. [27] indicated that the main spectral information (sensitive spectral bands and VIs) is sufficient to obtain 
high estimation accuracy, and our results were in agreement with their studies. The addition of Band 2 mean, Band 3 homogeneity, Band 3 dissimilarity, Band 3 entropy, Band 3 second moment, Band $3_{\text {correlation, and Band } 6 \text { mean further }}$ impoved the estimation accauracy of MRC based on Band $3_{\text {mean }}$, Band $4_{\text {mean, }}$ and Band 5 mean using PLSR (Table 5). These results suggested that Band $2_{\text {mean }}$, Band 3 homogeneity, Band 3 dissimilarity, Band $3_{\text {entropy, }}$

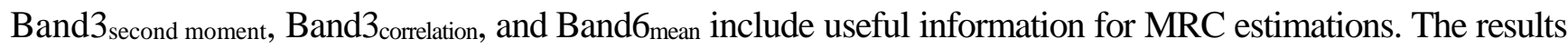
also demonstrated that textural feature indicators can be used to estimate MRC by PLSR. The results showed that the estimation accuracy of MRC was improved by the textural feature method based on all the textural feature indicators compared with the vegetation index methods based on all the VIs (Table 5). This may be because (1) the number of textural feature indicators was more than the number of VIs;

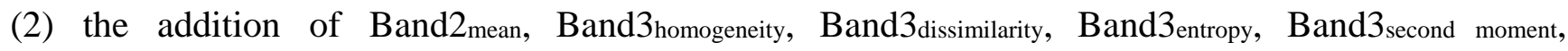
Band 3 correlation, and Band6mean contributed more useful information to MRC estimations than the addition of MCRC, NDI5, and NDSVI. The MRC estimation accuracy based on the VI or textural feature methods was improved with PLSR. This suggests that PLSR fully consider the covariance of VIs or textural features and MRC. The combination method obtained higher estimation accuracy of MRC based on the four VIs (NDTI, STI, NDI7, and SRNDI) and three textural feature indicators (Band3 mean, Band4 mean, and Band5mean) or all VIs and textural feature indicators using PLSR. The results show that the estimation accuracy of MRC was slightly improved based on all the VIs and textural feature indicators. In addition, the four VIs (NDTI, STI, NDI7, and SRNDI) and three textural feature indicators (Band $3_{\text {mean, }}$ Band 4 mean, and Band5 5 mean) were enough to obtain a high estimation accuracy of MRC. The results suggest that PLSR provides a better explanation in the same time of MRC, VIs, and textural feature indicators. Thus, PLSR is a useful tool that can be used to estimate several response variables simultaneously, while accounting for collinear variables. The combination method resulted in a stronger MRC model than that based on only spectral information (Table 5). Berberoglu et al. [48] and Kelsey and Neff [51] indicated that the combination of textural features and spectral information can further enrich the effective information. Thus, the combination method can be used to further improve MRC estimation accuracy (Table 5). In addition, this proved that it is feasible to estimate MRC by combining textural features and spectral information. Finally, the spatial distribution of MRC was mapped using the combination method. The crop residue cover mapping was used to classify tillage management strategies based on the spatial distribution of MRC. In soil carbon models, the spatial distribution of MRC, when implemented within a geographic information system, provides important boundary conditions on the dynamics of soil organic matter across landscapes. Our results provide a method for estimating MRC based on spectral information and textural features from remotely sensed signals in a regional scale. In some countries, the crop residue is spread evenly as the crop is harvested with a combine harvester. In this study, the maize residue cover (MRC) was estimated based on spectral information and textural features from Landsat-8 OLI images. Previous results have indicated differences in the spatial distribution of crop residue even when crops were harvested with a combine harvester, [2,10,14,47]. Therefore, this method can be used to estimate the uniform distribution of crop residue on a field scale. It is important to note that this study was limited to the two Landsat-8 OLI images obtained between Changchun in Jilin Province and Suihua in Heilongjiang Province, China. Future studies should obtain more Landsat-8 OLI images to verify the applicability of our results to different crops and environments. 


\section{Conclusions}

Textural features and VIs were investigated to determine the most accurate model for estimating MRC. The results showed that NDTI, STI, NDI7, and SRNDI were highly correlated with MRC. In particular, NDTI had a strong regression relationship with MRC, and the corresponding $\mathrm{R}^{2}$ and RMSE values of regression equation were 0.84 and $12.33 \%$, respectively. Band 3 mean had a stronger relationship with MRC than the other textural features, and the corresponding $\mathrm{R}^{2}$ and RMSE values of regression equation were 0.71 and $15.21 \%$, respectively. Band 3 mean, Band4 mean, and Band5mean were significantly correlated with MRC. The MRC estimation accuracy based on the combination method $\left(\mathrm{R}^{2}=0.96\right.$ and $\left.\mathrm{RMSE}=8.11 \%\right)$ was better than that based on the VI $\left(\mathrm{R}^{2}=0.88\right.$ and $\left.\mathrm{RMSE}=11.34 \%\right)$ and textural feature $\left(\mathrm{R}^{2}=0.90\right.$ and $\left.\mathrm{RMSE}=9.82 \%\right)$ methods.

\section{Acknowledgments}

This study was supported by the Key Deployment Project of Chinese Academy of Sciences (KZZD-EW-TZ-16-1).

\section{Author Contributions}

All authors conceived and designed the study. Xiuliang Jin made substantial contributions to the acquisition, analysis and interpretation of the data. Jianhang Ma, Zhidan Wen, and Kaishan Song performed the experiments. All authors discussed the basic structure of the manuscript, and Xiuliang Jin finished the first draft. Kaishan Song reviewed and edited the draft. All authors read and approved the submitted manuscript, agreed to be listed, and accepted the version for publication.

\section{Conflicts of Interest}

The authors declare no conflict of interest.

\section{References}

1. Bannari, A.; Haboudane, D.; Bonn, F. Intérêt du moyen infrarouge pour la cartographie desrésidus de cultures. Can. J. Remote Sens. 2000, 26, 384-393.

2. Daughtry, C.S.; Hunt, E.R., Jr.; Doraiswamy, P.C.; McMurtrey, J.E. Remote sensing the spatial distribution of crop residues. Agron. J. 2005, 97, 864-871.

3. Tomer, M.D. Assessing the extent of conservation tillage in agricultural landscapes. Proc. SPIE 2012, 8531, doi:10.1117/12.974611.

4. Bannari, A.; Staenz, K.; Champagne, C.; Khurshid, K.S. Spatial variability mapping of crop residue using Hyperion (EO-1) hyperspectral data. Remote Sens. 2015, 7, 8107-8127.

5. Aase, J.K.; Tanaka, D.L. Reflectance from four wheat residues cover densities as influenced by three soil backgrounds. Agron. J. 1991, 83, 753-757.

6. Ruane, J.; Sonnino, A.; Agostini, A. Bioenergy and the potential contribution of agricultural biotechnologies in developing countries. Biomass Bioenerg. 2010, 34, 1427-1439. 
7. Pacheco, A.; McNairn, H. Evaluating multispectral remote sensing and spectral unmixing analysis for crop residue mapping. Remote Sens. Environ. 2010, 114, 2219-2228.

8. Daughtry, C.S. Discriminating crop residues from soil by shortwave infrared reflectance. Agron. J. 2001, 93, 125-131.

9. Daughtry, C.S.T.; Hunt, E.R.; McMurtrey, J.E. Assessing crop residue cover using shortwave infrared reflectance. Remote Sens. Environ. 2004, 90, 126-134.

10. Bannari, A.; Pacheco, A.; Staenz, K.; McNairn, H.; Omari, K. Estimating and mapping crop residues cover on agricultural lands using hyperspectral and IKONOS data. Remote Sens. Environ. 2006, 104, 447-459.

11. Galloza, M.S.; Crawford, M.M.; Heathman G.C. Crop residue modeling and mapping using Landsat, ALI, Hyperion and airborne remote sensing data. IEEE JSTAR 2013, 6, 446-456.

12. Gausman, H.W.; Gerbermann, A.H.; Wiegand, C.L.; Leamer, R.W.; Rodriguez, R.R.; Noriega, J.R. Reflectance differences between crop residues and bare soils. Soil Sci. Soc. Am. J. 1975, 39, $752-755$.

13. Daughtry, C.S.; Hunt, E.R. Mitigating the effects of soil and residue water contents on remotely sensed estimates of crop residue cover. Remote Sens. Environ. 2008, 112, 1647-1657.

14. Serbin, G.; Hunt, E.R.; Daughtry, C.S.; McCarty, G.W.; Doraiswamy, P.C. An improved ASTER index for remote sensing of crop residue. Remote Sens. 2009, 1, 971-991.

15. McNairn, H.; Protz, R. Mapping corn residue cover on agricultural fields in Oxford County, Ontario, using Thematic Mapper. Can. J. Remote Sens. 1993, 19, 152-159.

16. Van Deventer, A.P.; Ward, A.D.; Gowda, P.H.; Lyon, J.G. Using thematic mapper data to identify contrasting soil plains and tillage practices. Photogramm. Eng. Remote Sens. 1997, 63, 87-93.

17. Qi, J.; Marsett, R.; Heilman, P.; Biedenbender, S.; Goodrich, D. Ranges improves satellite based information and land cover assessments in Southwest United States. Eos Trans. Am. Geophys. Union 2002, 83, 601-606.

18. Zheng, B.; Campbell, J.B.; de Beurs, K.M. Remote sensing of crop residue cover using multi-temporal Landsat imagery. Remote Sens. Environ. 2012, 117, 177-183.

19. Zheng, B.; Campbell, J.B.; Shao, Y.; Wynne, R.H. Broad-scale monitoring of tillage practices using sequential Landsat imagery. Soil Sci. Soc. Am. J. 2013, 77, 1755-1764.

20. Bocco, M.; Sayago, S.; Willington, E. Neural network and crop residue index multiband models for estimating crop residue cover from Landsat TM and ETM+ images. Int. J. Remote Sens. 2014, 35, 3651-3663.

21. Levine, M. Vision in Man and Machine; McGraw-Hill: New York, NY, USA, 1985.

22. Wood, E.M.; Pidgeon, A.M.; Radeloff, V.C.; Keuler, N.S. Image texture as a remotely sensed measure of vegetation structure. Remote Sens. Environ. 2012, 121, 516-526.

23. Beguet, B.; Guyon, D.; Boukir, S.; Chehata, N. Automated retrieval of forest structure variables based on multi-scale texture analysis of VHR satellite imagery. ISPRS J. Photogramm. Remote Sens. 2014, 96, 164-178.

24. Nichol, J.E.; Sarker, M.L.R. Improved Biomass Estimation Using the Texture Parameters of Two High-Resolution Optical Sensors. IEEE Trans. Geosci. Remote Sens. 2011, 49, 930-948. 
25. Darvishzadeh, R.; Skidmore, A.; Schlerf, M.; Atzberger, C.; Corsi, F.; Cho, M. LAI and chlorophyll estimation for a heterogeneous grassland using hyperspectral measurements. ISPRS J. Photogramm. Rem. Sens. 2008, 63, 409-426.

26. Li, X.; Zhang, Y.; Bao, Y.; Luo, J.; Jin, X.; Xu, X.; Song, X.; Yang, G. Exploring the best hyperspectral features for LAI estimation using Partial Least Squares Regression. Remote Sens. 2014, 6, 6221-6241.

27. Mutanga, O.; Adam, E.; Adjorlolo, C.; Abdel-Rahman, E.M. Evaluating the robustness of models developed from field spectral data in predicting African grass foliar nitrogen concentration using WorldView-2 image as an independent test dataset. Int. J. Appl. Earth Observ. 2015, 34, 178-187.

28. Oumar, Z.; Mutanga, O.; Ismail, R. Predicting Thaumastocoris peregrinus damage using narrow band normalized indices and hyperspectral indices using field spectra resampled to the Hyperion sensor. Int. J. Appl. Earth Observ. 2013, 21, 113-121.

29. Thenkabail, P.S.; Enclona, E.A.; Ashton, M.S.; van der Meer, B. Accuracy assessments of hyperspectral waveband performance for vegetation analysis applications. Remote Sens. Environ. 2004, 91, 354-376.

30. Ren, C.Y.; Zhang, C.H.; Wang, Z.M.; Zhang, B. Organic Carbon Storage and Sequestration Potentialin Cropland Surface Soils of Songne plain mazie belt. J. Nat. Resour. 2013, 28, 596-607. (In Chinese)

31. Morrison, J.E.; Huang, C.H.; Lightle, D.T.; Daughtry, C.S.T. Residue measurement techniques. J. Soil Water Conserv. 1993, 48, 478-483.

32. NRCS. Farming with Crop Residue Brochure. 1992. Available online: http://www.il.nrcs.usda.gov/ news/publications/brochures/farmcropres/FarmCropRes-broc.html (accessed on 15 March 2010).

33. Sullivan, D.G.; Truman, C.C.; Schomberg, H.H.; Endale, D.M.; Strickland, T.C. Evaluating techniques for determining tillage regime in the Southeastern Coastal Plain and Piedmont. Agron. J. 2006, 98, 1236-1246.

34. Richards, J.A. Remote Sensing Digital Image Analysis; Springer-Verlag: Berlin, Germany, 1999.

35. Abdi, H. Partial Least Square Regression (PLS Regression). In Encyclopedia of Measurement and Statistics; Salkind, N., Ed.; SAGE: Thousand Oaks, CA, USA, 2003; pp. 792-795.

36. Hansen, P.M.; Schjoerring, J.K. Reflectance measurement of canopy biomass and nitrogen status in wheat crops using normalized difference vegetation indices and partial least squares regression. Remote Sens. Environ. 2003, 86, 542-553.

37. Jin, X.L.; Xu, X.G.; Song, X.Y.; Li, Z.H.; Wang, J.H.; Guo, W.S. Estimation of leaf water content in winter wheat using grey relational analysis-partial least squares modeling with hyperspectral data. Agron. J. 2013, 105, 1385-1392.

38. Wang, B.S. Field-Experiment and Statistic-Method; Chinese Agriculture Press: Beijing, China, 2002.

39. Murray, I.; Williams, P.C. Chemical principles of near-infrared technology. In Near-Infrared Technology in the Agricultural and Food Industries; Williams, P., Norris, K., Eds.; American Association of Cereal Chemists: St. Paul, MN, USA, 1988; pp. 17-34.

40. Annea, N.J.P.; Abd-Elrahman, A.H.; Lewis, D.B.; Hewitta, N.A. Modeling soil parameters using hyperspectral image reflectance in subtropical coastal wetlands. Int. J. Appl. Earth Observ. 2014, 33, 47-56. 
41. Franceschini, M.H.D.; Demattêa, J.A.M.; da Silva Terra, F; Vicente, L.E.; Bartholomeus, H.; de Souza Filho, C.R. Prediction of soil properties using imaging spectroscopy: Considering fractional vegetation cover to improve accuracy. Int. J. Appl. Earth Observ. 2015, 38, 358-370.

42. Jia, M.M.; Zhang, Y.Z.; Wang, Z.M.; Song, K.S.; Ren, C.Y. Mapping the distribution of mangrove species in the Core Zone of Mai Po Marshes Nature Reserve, Hong Kong, using hyperspectral data and high-resolution data. Int. J. Appl. Earth Observ. 2014, 33, 226-231.

43. Lagacherie, P.; Sneep, A.R.; Gomez, C.; Bacha, S.; Coulouma, G.; Hamrouni, M.H.; Mekki, I. Combining Vis-NIR hyperspectral imagery and legacy measured soil profiles to map subsurface soil properties in a Mediterranean area (Cap-Bon, Tunisia). Geoderma 2013, 209-210, 168-176.

44. Liu, S.H.; An, N.N.; Yang, J.J.; Dong, S.K.; Wang, C.; Yin, Y.J. Prediction of soil organic matter variability associated with different land use types in mountainous landscape in southwestern Yunnan province, China. Catena 2015, 133, 137-144.

45. Peng, X.; Shi, T.; Song, A.; Chen, Y.; Gao, W. Estimating soil organic carbon using VIS/NIR spectroscopy with SVMR and SPA methods. Remote Sens. 2014, 6, 2699-2717.

46. Wanjura, D.F.; Bilbro, J.D. Ground cover and weathering effects on reflectance of three crop residues. Agron. J. 1986, 78, 694-698.

47. Daughtry, C.S.; Doraiswamym P.; Hunt, E.R.; Stern, A.; McMurtrey, J.E.; Prueger, J. Remote sensing of crop residue cover and soil tillage intensity. Soil Tillage Res. 2006, 91, 101-108.

48. Berberoglu, S.; Lloyd, C.D.; Atkinson, P.M.; Curran, P.J. The integration of spectral and textural information using neural networks for land cover mapping in the Mediterranean. Comput. Geosci. 2000, 26, 385-396.

49. Lu, D. The potential and challenge of remote sensing-based biomass estimation. Int. J. Remote Sens. 2006, 27, 1297-1328.

50. Zhou, J.; Zhao, Z.; Zhao, J.; Zhao, Q.; Wang, F.; Wang, H. A comparison of three methods for estimating the LAI of black locust. Int. J. Remote Sens. 2014, 35, 171-188.

51. Kelsey, K.; Neff, J. Estimates of aboveground biomass from texture analysis of Landsat imagery. Remote Sens. 2014, 6, 6407-6422.

52. Fourty, T.; Baret, F. Vegetation water and dry matter contents estimated from top-of-the-atmosphere reflectance data: A simulation. Remote Sens. Environ. 1997, 61, 34-45.

(C) 2015 by the authors; licensee MDPI, Basel, Switzerland. This article is an open access article distributed under the terms and conditions of the Creative Commons Attribution license (http://creativecommons.org/licenses/by/4.0/). 